\title{
ALCOHOL CONSUMPTION AMONG ADOLESCENTS IN THE BRČKO DISTRICT OF BOSNIA AND HERZEGOVINA: RESULTS FROM A CROSS-SECTIONAL POPULATION-BASED STUDY
}

\author{
${ }^{1}$ Government of Brčko District of Bosnia \\ and Herzegovina, ${ }^{2}$ Academy of Sciences and \\ Arts of Bosnia and Herzegovina, Sarajevo \\ Bosnia and Herzegovina, ${ }^{3}$ Institute for \\ Biostatistics and Medical Informatics \\ Faculty of Medicine, Ljubljana, Slovenia
}

Anto DOMIĆ ${ }^{1}$, Husref TAHIROVIĆ ${ }^{2}$ Mojca ČIŽEK SAJKO

\author{
Corresponding author: \\ Anto Domić \\ Government of Brčko District BH \\ Bulevar mira 1 \\ 76100 Brčko \\ Bosnia and Herzegovina \\ anto.domic67@gmail.com \\ Tel.: + 38749240600 \\ Fax.: + 38749490020
}

Received: December 12, 2014

Accepted: February 3, 2015

Copyright (C) 2015 by

University Clinical Centre Tuzla.

E-mail for permission to publish:

paediatricstoday@ukctuzla.ba
Objective - The present study was undertaken to determine alcohol consumption among adolescents attending state schools in the Brčko District of Bosnia and Herzegovina $(\mathrm{BH})$. Participants and method - The subjects were pupils in the ninth grade of elementary school and all high school pupils. 4,188 pupils took part in the survey. The research was planned as a cross-sectional study, and it was conducted using the ESPAD questionnaire, which was adjusted for this research. Demographic data were collected through a specific question-form for each enrolled adolescent. Results - More than half the adolescents consumed alcohol. Boys did so more often, whilst there was no difference in alcohol consumption between those who lived in villages or towns. At the age of 14 years nearly half the adolescents had consumed alcohol, where boys had done so more often, as well as the adolescents from villages. The places where the adolescents most often consumed alcohol were discotheques, "at friends' homes", and in cafés. More than half the members of the adolescents' households consume alcohol. Adolescents in the Brčko District of $\mathrm{BH}$ had consumed alcohol over the previous 30 days in a significantly higher percentage than pupils from the Republic of Srpska and the Federation of BH, and in a significantly lower percentage than pupils from Croatia, whilst the difference in comparison with Serbia was not significant. The frequency of alcohol intoxication in the Brčko District of $\mathrm{BH}$ was the lowest in comparison with the Republic of Srpska, the Federation of BH, Croatia and Serbia. Conclusion - Overall alcohol consumption amongst adolescents is becoming generally acceptable behaviour, which is tolerated by the community and parents, in that alcohol consumption is becoming a life-style, but it is not being systematically studied as a negative phenomenon, nor are there any long-term programmes to deter adolescents from consuming alcohol.

Key words: Alcohol - Adolescence - Brčko District of BH • Epidemiology $=$ Drinking.

\section{Introduction}

Adolescence is a period of dramatic biological change - occurring in the context of equally dynamic socio-environmental change with regard to the adolescent's school, peer group, family, and social milieu (1). During this dynamic period, the first initiation to alcohol consumption takes place. Although serious chronic health problems from drinking alcohol in adolescence are not so frequent, 
they still occur. The adolescent brain is still maturing, so the study of the effects of alcohol is more complex (2). Also, the most serious consequences of alcohol consumption in adolescence are lethal outcomes for the adolescents themselves, or others.

Heavy adolescent drinkers exhibit decrements in memory (3) and learning functioning (4). Also, many research studies have indicated a link between alcohol consumption in adolescence and violent and aggressive behaviour $(5,6)$, risk factor for injuries $(7,8)$, traffic accidents (9), risky sexual behaviour $(10,11)$, poor school achievement $(12,13)$, and a greater risk for the development of alcohol dependency and psychological distress later in life $(14,15)$.

According to the European School Survey Project on Alcohol and Other Drugs (ESPAD) 2011, (16) an average of $87 \%$ of subjects with a mean age of 15.8 years in 36 countries had drunk alcohol at least once in their lifetime. This project in Bosnia and Herzegovina $(\mathrm{BH})$ was only carried out in the Republic of Srpska. In this entity of BH, $47 \%$ students had consumed alcohol over the previous 30 days. Later research included the Federation of $\mathrm{BH}$ and it was established that in this entity of $\mathrm{BH} 43 \%$ students had consumed alcohol over the previous 30 days (17). In the neighbouring countries to the Brčko District $\mathrm{BH}$, according to the same study (16) 66\% students from Croatia and $52 \%$ students from Serbia had consumed alcohol over the previous 30 days. In other European countries these averages differ, varying from $79 \%$ in the Czech Republic to only $17 \%$ in Iceland (16).

The ESPAD 2011 study (16) did not include the area of the Brčko District of $\mathrm{BH}$, which is neutral, self-governing administrative unit, under the sovereignty of $\mathrm{BH}$, located in the north-east of $\mathrm{BH}$, and an important crossroads of national and international routes, connecting the East with the West and the North with the South.
With this background, the present study was undertaken to determine alcohol consumption among adolescents attending state schools in the Brčko District of BH. We investigated the age of their first consumption of alcohol, according to gender, place of residence, as well as the places where adolescents usually consume alcohol. Also, this study investigated the frequency of consumption of any alcohol beverage and the frequency of alcohol intoxication over the previous 30 days, and compared this data with data from the ESPAD study $(16,17)$ for the Federation of $\mathrm{BH}$ and the Republic of Srpska, as well as the neighbouring countries, Croatia and Serbia.

\section{Participants and methods}

\section{Area of research}

The area of the Brčko District of $\mathrm{BH}$, (Fig. 1) covers $493.3 \mathrm{~km} 2$, where in 2011 the population was 75,625 , with an average density of 153 inhabitants per square kilometre, which is a higher density than some areas in the immediate vicinity. Of the total population, $24.2 \%$ are children and adolescents. In 2011, a total of 905 children were born in the area of the Brčko District of $\mathrm{BH}$, the birth rate is $11.9 \%$, whilst the natural growth rate of the population is negative, at $-0.6 \%$ (18).

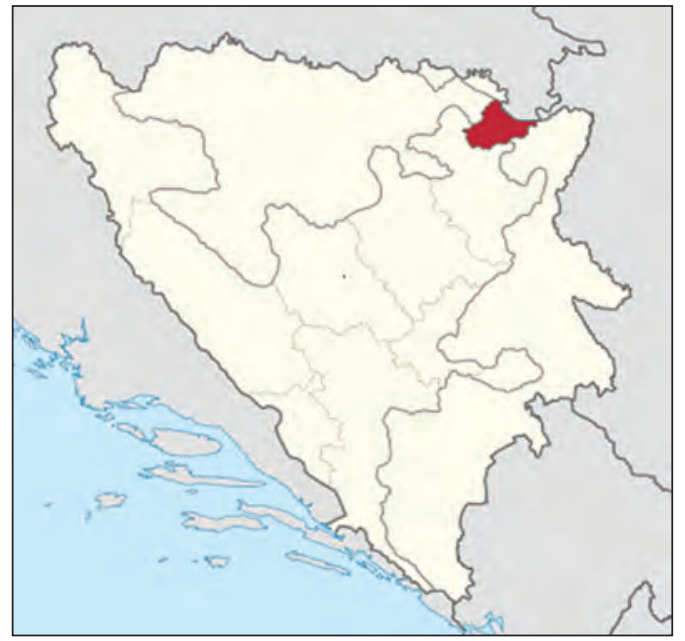

Fig. 1 The Area of the Brcko District BH (coloured red). 


\section{Subjects}

The subjects of this research are pupils in the ninth grade of elementary school and pupils of all four grades of high schools in the Brčko District of BH. The total number of pupils was 4,676 . Of that number, 1016 were ninth grade pupils from 12 elementary schools, with local subsidiaries, and 3660 high school pupils, from 4 high schools. The study was conducted on 4188 or $89.6 \%$ of pupils.

\section{Methods}

The research was planned as a cross-sectional study, using an ESPAD questionnaire (16) adapted for this research, translated into the official languages of $\mathrm{BH}$. This questionnaire was created by a group of experts from the European Monitoring Centre for Drugs and Drug Addiction (EMCDDA) and the Pompidou Group (16), founded by the Council of Europe, with the aim that the results of research into alcohol consumption and the use of narcotics in various countries could be compared and analysed. The questionnaire contains 45 questions, divided into the appropriate thematic units. Demographic data were collected through a specific questionform for each enrolled adolescent.

After prior approval had been given by the head teacher and teachers of the schools, the research was conducted in the 2011/2012 school year during a single school lesson in the period from 20 October 2011 to 28 November 2011 . The pupils filled in the questionnaire themselves following an explanation by a person who had been especially trained in how to fill in the specific questionnaire. The person supervising the research helped the pupils to fill in the questionnaire, by explaining the questions, but did not have any influence on their final response. After filling in the questionnaire, the pupils placed them in an envelope, which they sealed and handed to the person supervising the questionnaire. For this article, the following answers by the adolescents from the completed questionnaires were used: When the adolescent had consumed an alcoholic drink for the first time; Where they most often consumed alcohol; Whether one of their household members consumed alcohol; How many times they had consumed alcohol and how many times they had been intoxicated over the previous 30 days. The age of the first consumption of alcoholic drinks was analysed in relation to the adolescents' gender, age and place of residence (village-town).

\section{Ethical aspects of the research}

The subjects who filled in the questionnaire were informed of the reasons, purpose and goal of the research. They agreed voluntarily to the anonymous research, whose results would be used exclusively for scientific purposes. The people who assisted with the questionnaire did not have access to the completed questionnaires, because the subjects placed them in envelopes and sealed the envelopes themselves. The questionnaires were designed on the basis of the ESPAD questionnaires, which guarantee a scientific approach and represent the best European practice in research into the use of narcotic drugs.

\section{Statistical analysis}

The prevalence of individual replies to the questions asked in the questionnaire are presented as absolute and relative frequencies, and we have shown them in tables and graphics. The difference between observed and expected frequencies was estimated using Pearson's chi-squared test. A p value below 0.05 was set as statistically significant. SPSS 20 software (SPSS Inc., Chicago, IL, USA) was used for statistical analyses. 


\section{Results}

Of the 4188 subjects, 4084 gave information about their gender, and 2013 (49.3\%) were boys and $2071(50.7 \%)$ were girls. Of this number, in reply to the question: "Have you ever consumed any alcoholic drink before?" 98 subjects did not give any reply, so the prevalence of alcohol consumption between the genders was calculated for a sample of 3958 subjects, of which 1945 (49.1\%) were boys, and 2013 (50.9\%) were girls. 4062 subjects replied to the question "Do you live in a town or a village?" However, 125 subjects did not reply to the question: "Have you ever consumed any alcoholic drink before?" so the prevalence of alcohol consumption be- tween villages and towns was calculated for a sample of 3937 subjects.

Table 1 shows the results for alcohol consumption among students in the Brčko District of $\mathrm{BH}$ by gender and place of residence.

$41.1 \%$ stated that they had never consumed alcohol, in comparison with 58.9\% who had consumed alcohol in their lives. Alcohol was more frequently consumed by boys in comparison with girls (63.9\%:54.0\%, $\mathrm{p}<0.001)$ whilst the prevalence of alcohol consumption amongst adolescents who lived in a village in comparison with those who lived in a town $(59.1 \%: 58.7 \%, \mathrm{p}=0.867)$ was almost equal.

Table 2 shows the results for the age at first consumption of alcohol for students liv-

\begin{tabular}{|c|c|c|c|}
\hline & \multicolumn{3}{|c|}{ Alcohol consumption by students in the Brčko District of BH } \\
\hline & No $(\mathrm{n} ; \%)$ & Yes $(\mathrm{n} ; \%)$ & Total \\
\hline \multicolumn{4}{|l|}{ Gender } \\
\hline Male & $702(36.1)$ & $1243(63.9)$ & $1945(100)$ \\
\hline Female & $926(46)$ & $1087(54.0)$ & $2013(100)$ \\
\hline Total & $1628(41.1)$ & $2330(58.9)$ & $3958(100)$ \\
\hline \multicolumn{4}{|c|}{ Place of residence } \\
\hline Urban & $733(41.3)$ & $1042(58.7)$ & $1775(100)$ \\
\hline Rural & $886(40.9)$ & $1276(59.1)$ & $2162(100)$ \\
\hline Total & 1619 (41.1) & $2318(58.9)$ & $3937(100)$ \\
\hline
\end{tabular}

\begin{tabular}{|c|c|c|c|c|c|}
\hline & \multicolumn{5}{|c|}{ Alcohol consumption } \\
\hline & \multirow{2}{*}{$(\mathrm{n} ; \%)$} & \multicolumn{4}{|c|}{ Age at first consumption of alcohol (n; \%) } \\
\hline & & $\leq 13$ years & 14 years & 15 years & 16 years \\
\hline \multicolumn{6}{|l|}{ Gender } \\
\hline Female & $1087(46.6)$ & $395(36.3)$ & $232(21.3)$ & $225(20.7)$ & $235(21.7)$ \\
\hline Male & $1243(53.4)$ & $697(56.1)$ & $237(19.1)$ & $174(14.0)$ & $135(10.8)$ \\
\hline Total & $2330(100)$ & $1092(46.9)$ & $469(20.1)$ & $399(17.1)$ & $370(15.9)$ \\
\hline \multicolumn{6}{|c|}{ Place of residence } \\
\hline Rural & $1276(55.0)$ & $628(49.2)$ & $226(17.7)$ & $217(17.0)$ & $205(16.1)$ \\
\hline Urban & $1042(45.0)$ & $463(44.4)$ & $238(22.8)$ & $179(17.2)$ & $162(15.6)$ \\
\hline Total & $2318(100)$ & $1091(47.0)$ & $464(20.1)$ & $396(17.1)$ & $367(15.8)$ \\
\hline
\end{tabular}


ing in the Brčko District of $\mathrm{BH}$ by gender and place of residence.

On average $46.9 \%$ of subjects who had consumed alcohol did so at the age of 14 years. At that age, alcohol was consumed more often by boys in comparison with girls $(56.1 \%: 36.3 \%, \mathrm{p}<0.001)$ whilst girls consumed alcohol more frequently at the ages of 15 and $16(p<0.001)$. Adolescents from villages more often consumed alcohol before they were 14 than adolescents from towns (49.2\%:44.4\%, $\mathrm{p}=0.024)$, adolescents from towns did so at the age of 14 more often $(22.8 \%: 17.7 \%, \mathrm{p}=0.003)$ however, the prevalence of alcohol consumption by ado- lescents from villages and those from towns was almost equal at the ages of 15 and 16 $(\mathrm{p}>0.05)$.

The places where students usually consume alcohol are presented in Fig. 1 .

Several possible replies were offered to the question. Of the 4188 adolescents who completed the questionnaire, 2395 (57.2\%) of them replied to the question about the place where they most often consumed alcohol. According to their replies, 1233 (51.4\%) of them most often consumed alcohol in a discotheque, $1229(51.3 \%)$ at a friend's home, $953(39.7 \%)$ in a bar, $168(7 \%)$ on the street, and $92(3.8 \%)$ in school.

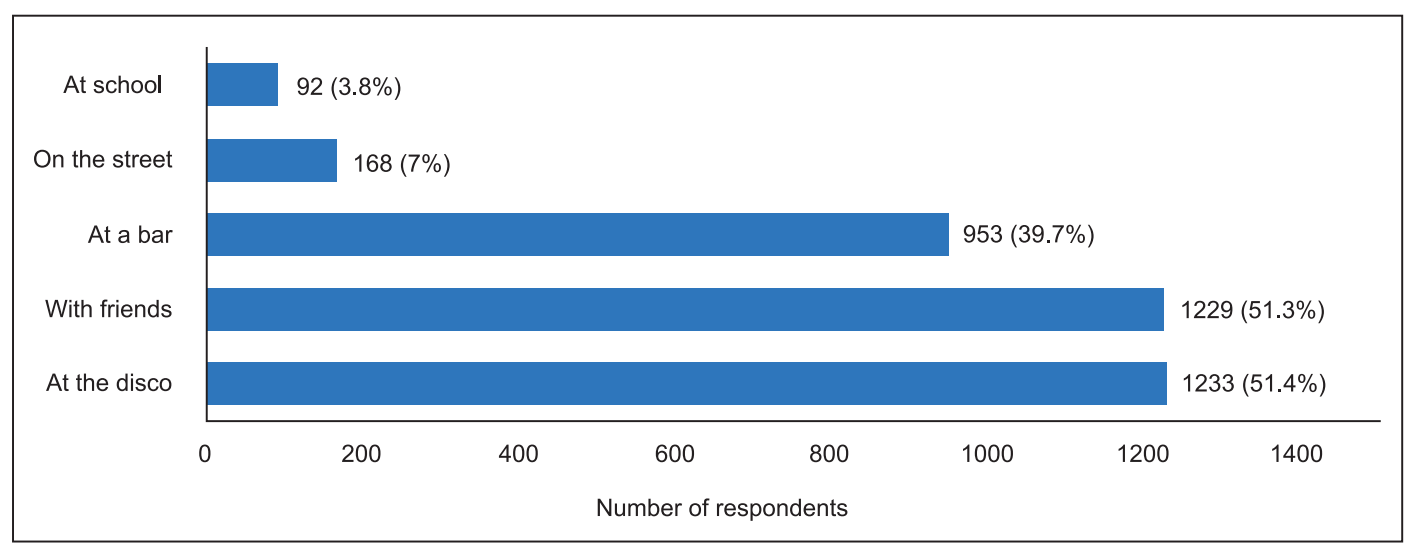

Fig. 1 The replies to the question: "Where do you most frequently consume alcohol?" Several possible replies were offered to the question.

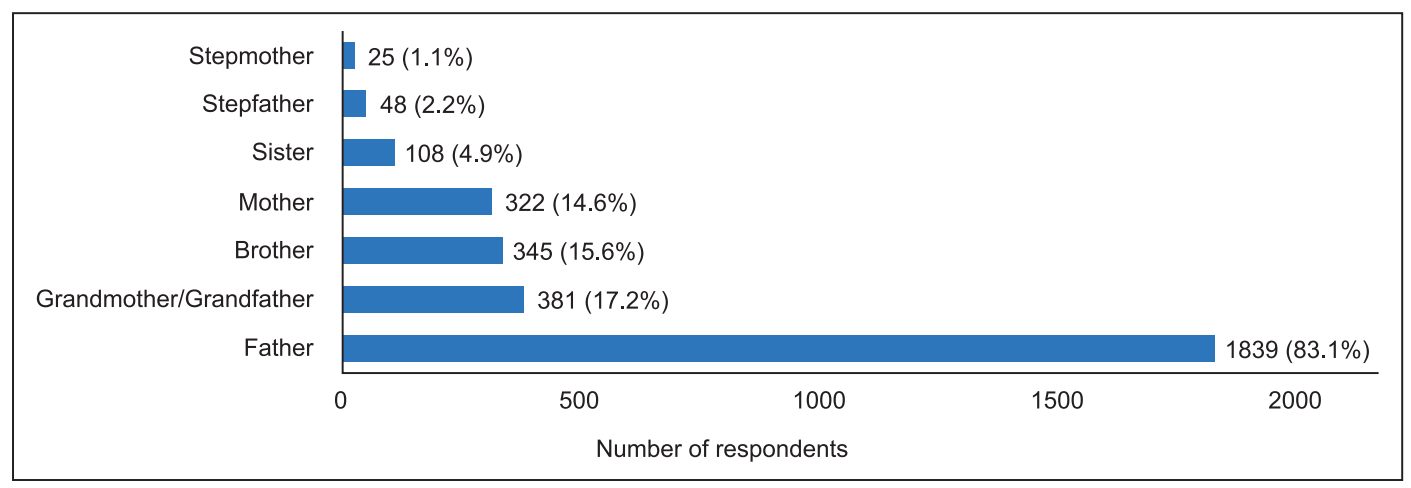

Fig. 2 The replies to the question: "Do any of the people in your household drink alcohol?" Several possible replies were offered to the question. 
The replies to the question: "Do any of the people in your household drink alcohol?" are shown in Fig. 2.

$2213(52.8 \%)$ of subjects replied that members of the household in which the adolescent lives consumed alcohol. Of that number, alcohol was consumed by more than $80 \%$ of fathers, in every 7 th family the mother consumes alcohol, and alcohol consumption by brothers, grandmothers and grandfathers is in the same proportion, whilst only $5 \%$ of sisters consume alcohol.

Fig. 3 shows the prevalence of consumption of any form of alcoholic beverage in the previous 30 days.
Of the 4188 subjects who took part in the questionnaire, 3800 of them $(80.7 \%)$ gave a reply to the question about the prevalence of consumption of any form of alcoholic beverage in the previous 30 days. Of that number almost half the subjects $(47.1 \%)$ had not consumed any alcoholic beverage, whilst $19.7 \%$ of them had consumed alcohol 1-2 times, $12.6 \%$ 3-5 times, whilst $4.1 \%$ of subjects had consumed alcohol 40 times or more in the previous 30 days.

Fig. 4 shows the prevalence of alcohol intoxication in the previous 30 days.

Of 3883 subjects who replied to this question on alcohol intoxication, most subjects $(87.2 \%)$ stated that they had never been

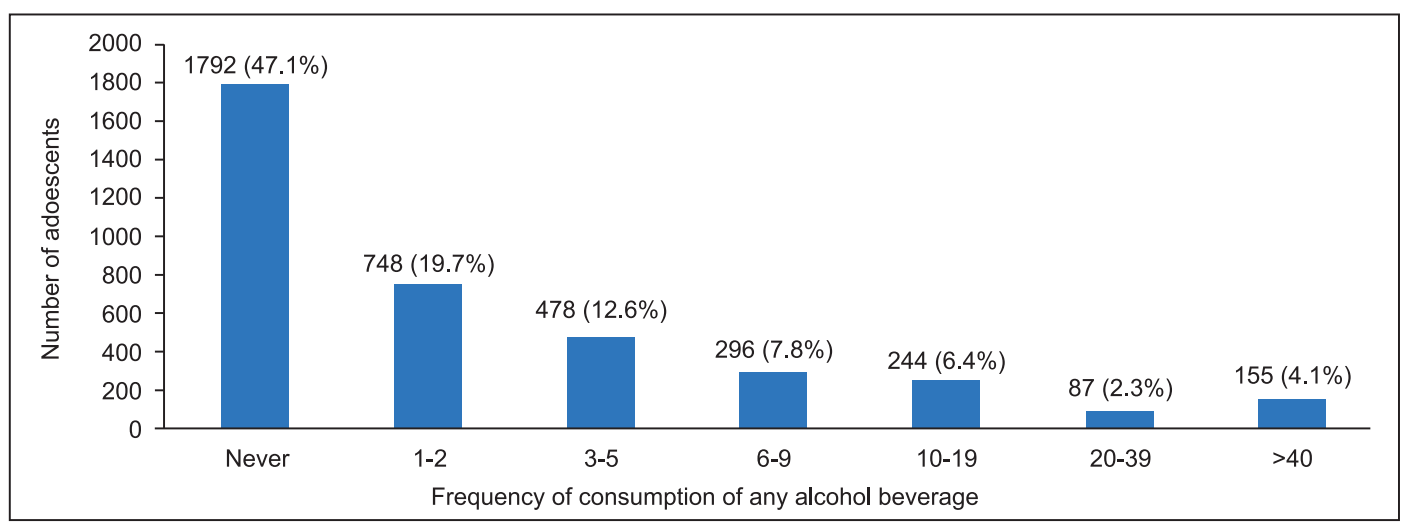

Fig. 3 Frequency of consumption of any alcoholic beverage in the previous 30 days.

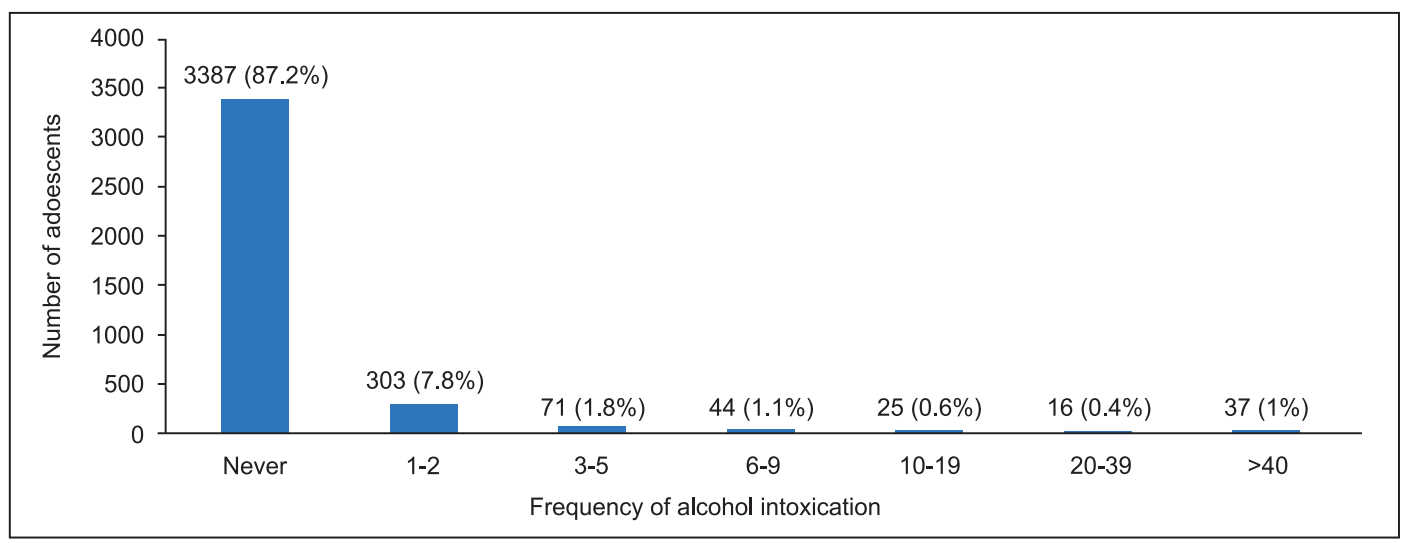

Fig. 4 Frequency of alcohol intoxication in the previous 30 days. 
intoxicated by alcohol. Adolescents had been intoxicated mostly once or twice, whilst $1 \%$ had been intoxicated as many as 40 times or more in the previous 30 days.

The replies by the subjects on alcohol consumption in the previous 30 days and the prevalence of alcohol intoxication were compared with the results of the ESPAD study (17).

According to this study a positive (Yes) reply was given to the question about alcohol consumption in the previous 30 days by $47 \%$ (1472/3132) of pupils from the Republic of Srpska, 43\% (1639/3813) from the Federation of BH, $66 \%(1981 / 3002)$ from the Croatia and 52\% (3164/6084) from the Serbia. In relation to the figures from the Brčko District of $\mathrm{BH}$, where the prevalence of alcohol consumption was $52.9 \%(2008 / 3800)$ it is noticeable that a significantly higher percentage of subjects from the Brčko District of $\mathrm{BH}$ had consumed alcohol in the previous 30 days than pupils from the Republic of Srpska BH $(p<0.001)$ and from the Federation of $\mathrm{BH}$ $(\mathrm{p}<0.001)$, but a significantly lower percentage than pupils from the Croatia $(\mathrm{p}<0.001)$, whilst the difference in prevalence of alcohol consumption between pupils from the Brčko District of $\mathrm{BH}$ and pupils from the Serbia was not statistically significant $(\mathrm{p}=0.392)$.

According to our research, the prevalence of alcohol intoxication in the Brčko District of $\mathrm{BH}$ was $12.9 \%(506 / 3921)$ and it was statistically significantly lower $(\mathrm{p}<0.001)$ than the figures from the ESPAD study (17) for the Republic of Srpska (31\%; 971/3132), the Federation of $\mathrm{BH}(34 \% ; 1296 / 3813)$, the Serbia $(36 \% ; 2190 / 6084)$ and the Croatia $(54 \% ; 1621 / 3002)$.

\section{Discussion}

More than half the adolescents who took part in our study had consumed some form of alcoholic beverage. This was more often true of boys than of girls, whilst between the adoles- cents who live in towns and those who live in villages there was almost no difference in the prevalence of alcohol consumption. It is interesting to notice that of the total number of adolescents who consumed alcohol, almost half of them had already tried an alcoholic beverage at an early age, that is at the age of 13 or younger, and that boys did so more often than girls, and adolescents of that age from villages were more likely to consume alcohol than those from a town.

Looking at the social aspects of the environment in which our adolescents live, it was to be expected that the prevalence of alcohol consumption would be high and that boys would more often consume alcohol than girls. That is to say, our subjects mainly come from households where the parents consume alcohol, and according to the customs of our setting, regardless whether they live in a village or a town, and boys are more often with their fathers who frequently drink alcohol in various circumstances, or at least talk about it. It is not at all rare for boys to participate in the production of "rakija" (distilling) with their fathers, as this is a traditional custom in this region. Overall, alongside the general social tolerance of consumption of alcoholic beverages, this most probably influenced the decision by the adolescents to begin to drink alcohol at an early age.

Bearing this in mind, we wanted to ask adolescents where they most often consumed alcohol. From the answers we collected to that question, we established that every other adolescent consumes alcohol in discotheques, the same number "at a friend's home", and slightly less than one third do so in a bar. This high level of alcohol consumption in public places leads to the conclusion that society as a whole is highly tolerant of adolescents regarding consumption of alcohol, or even supports it. The results obtained indicating that adolescents start consuming some form of alcoholic beverage at an early age are worrying, because it is well-known that early consump- 
tion of alcohol leads in later life to the more frequent development of alcoholism $(14,15$, 19), which endangers the social situation of individuals and families, and also causes a great deal of harm to society as a whole.

There is a similar prevalence of alcohol consumption amongst adolescents in the countries included in the ESPAD research, where it was established that on average in $2011,87 \%$ of subjects had consumed alcohol at least once in their lives (16) which is more often than in the Brčko District of BH. The research relating to alcohol consumption in $\mathrm{BH}$ was conducted separately for the different entities: the Federation of $\mathrm{BH}$ and the Republic of Srpska (17), whilst in the Brčko District of $\mathrm{BH}$ research on alcohol consumption amongst adolescents had not been conducted before. This splintered approach in our country makes it difficult to form a clear picture of alcohol consumption and to create united policies for prevention of alcohol consumption amongst adolescents.

According to the ESPAD research (16, 17) on average for all countries $57 \%$ of subjects had consumed alcohol in the previous 30 days, which is slightly more than the adolescents from the Brčko District of $\mathrm{BH}$. On the basis of these figures, it may be concluded that adolescents from the Brčko District of $\mathrm{BH}$ consume alcohol less frequently than adolescents in countries covered by the ESPAD studies $(16,17)$, and it may be assumed that the Brčko District of $\mathrm{BH}$ is an environment with developed programmes for prevention of alcohol consumption by adolescents. However, this assumption is inaccurate, and these "favourable" results should rather be interpreted as the possible lack of honesty on the part of the subjects in giving their answers, perhaps because of a lack of confidence in the anonymity of the research, or the fear that the data would be used for purposes which would not be favourable for them. On the other hand, the general social acceptance of alcohol consumption is great, and it is probable that the subjects believed a minimal consumption of alcohol to be unimportant, such as drinking just one drink for instance.

Due to the overriding perception of the prevalence of alcohol consumption in the Brčko District of $\mathrm{BH}$, we presumed that adolescents in the Brčko District of $\mathrm{BH}$ consumed alcohol more often than their peers in the entities of $\mathrm{BH}$ (the Federation of $\mathrm{BH}$ and the Republic of Srpska) and the neighbouring countries, primarily Croatia and Serbia. The analysis of our figures and the figures from the ESPAD study $(16,17)$ showed that there was a statistically significant difference in the frequency of alcohol consumption amongst adolescents in the Brčko District of $\mathrm{BH}$ in the previous 30 days, in comparison with adolescents from the Republic of Srpska and adolescents from the Federation of $\mathrm{BH}$. However, when the situation in Croatia and Serbia is considered, we find that in Croatia more than one fifth of adolescents consume alcohol $(16,17)$, which is statistically significantly more than in the Brčko District of $\mathrm{BH}$, whilst the consumption of alcohol in Serbia is at the same level as in the Brčko District of $\mathrm{BH}$.

The phenomenology of alcohol consumption in adolescents is influenced to a major extent by the so-called environmental factors present in each community, as well as the lawful, economic, physical and social availability of alcohol (20). It is well-known that adolescence is a period of growing up, and in that period adolescents tend to identify with their role models or idols, which may be a trigger for uncontrolled alcohol consumption (21). Adolescents may start drinking alcohol by themselves, prompted by the public and indiscriminate consumption of alcohol by members of their household. In our research more than half the adolescents stated that members of their household consumed alcohol, which confirms the high level of 
tolerance of parents regarding alcohol consumption, or even their support for it. From this it clearly stems that the habit of alcohol consumption is passed on through the family culture, that is, the parents' relationship towards the use of alcohol is very important. Furthermore, the availability of alcohol, due to the failure to respect the law, enables young people to obtain alcohol without any hindrance or sanctions, and to consume it in public premises, public areas, and in discotheques and cafés.

Alongside the prevalence of alcohol consumption we also researched the prevalence of alcohol intoxication in subjects over the previous 30 days in the Brčko District of $\mathrm{BH}$. By analysis of the results obtained and comparison of them with figures published in the ESPAD reports $(16,17)$, we saw that the prevalence of alcohol consumption amongst adolescents in the Brčko District of $\mathrm{BH}$ is more or less the same as in the neighbouring countries, whilst the prevalence of alcohol intoxication was the lowest in the subjects from the Brčko District of $\mathrm{BH}$. This needs to be investigated further in order to exclude the possibility of error, and to establish which factors lead to the rare occurrence of intoxication amongst adolescents who consume alcohol in the Brčko District of BH.

\section{Limitations of the study}

One of the weaknesses of this research is the lack of data on possible alcohol dependency amongst adolescents in the Brčko District of $\mathrm{BH}$. Additional research in that regard would be useful, because the picture of alcohol consumption in the Brčko District of $\mathrm{BH}$ would be more complete, which would be important for creation of a programme for prevention of alcohol consumption in this environment. Another weakness is that in the preparation of this research, no complete or serious preparations were undertaken of the subjects by school pedagogues and psychologists, to explain to the adolescents the importance of the research and the need to give exact replies, because in so doing, the number of incomplete questionnaires and dishonest replies would have been reduced to a minimum.

\section{Conclusion}

More than half the adolescents in the Brčko District of BH had tried alcohol at least once in their lives, and of that number every other one had done so before they were thirteen years old. The boys consumed alcohol more than the girls, whilst their place of residence did not have any influence on the prevalence of alcohol consumption. In relation to the adolescents in the entities of Bosnia and Herzegovina - the Federation of $\mathrm{BH}$ and the Republic of Srpska, adolescents in the Brčko District of $\mathrm{BH}$ consumed alcohol more often, which was not the case in comparison with their peers from neighbouring countries - the Croatia and the Serbia. Taken overall, alcohol consumption is becoming generally acceptable behaviour, tolerated both by the community and parents, which results in the fact that alcohol consumption is becoming a life-style, but it is not being studied systematically as a negative phenomenon, nor are there any long-term programmes to deter adolescents from consuming alcohol.

Authors' contributions: Conception and design: AD, HT, MČS, Acquisition, analysis and interpretation of data: AD, MČS; Drafting the article AD, HT, MČS; Revising it critically for important intellectual content: AD, HT, MČS.

Conflict of interest: The authors declare that they have no conflict of interest.

\section{References}

1. National Institute on Alcohol Abuse and Alcoholism: Five-year strategic plan (FY07-11) alcohol 
across the lifespan. [cited 2015 Feb 1] Available from: http://www.pubs.niaaa.nih.gov/publications/ StrategicPlan/ NIAAASTRATEGI CPLAN.htm.

2. The National Institute on Alcohol Abuse and Alcoholism. Underage drinking. Alkohol Alert. 2006;67:1-7. [cited 2015 Feb 1] Available from: http://www.niaaa.nih.gov.

3. Brown SA, Tapert SF, Granholm E, Delis DC. Neurocognitive functioning of adolescents: effects of protracted alcohol use. Alcohol Clin Exp Res. 2000;24(2):164-71.

4. Squeglia L, Jacobus J, Tapert S: The influence of substance use on adolescent brain development. Clin EEG Neurosci. 2009;40:31-8.

5. White HR, Fite P, Pardini D, Mun EY, Loeber R. Moderators of the dynamic link between alcohol use and aggressive behavior among adolescent males. J Abnorm Child Psychol. 2013;41(2):21122.

6. White HR, Brick J, Hansell S. A longitudinal investigation of alcohol use and aggression in adolescence. J Stud Alcohol Suppl. 1993;11:62-77.

7. Paiva PC, Paiva HN, Oliveira Filho PM, Lamounier JA, Ferreira RC, et al. Prevalence of traumatic dental injuries and its association with binge drinking among 12-year-olds: a population-based study. Int J Paediatr Dent. 2014. doi: 10.1111/ ipd.12135.

8. Kuntsche E, Gmel G. Alcohol consumption in late adolescence and early adulthood--where is the problem? Swiss Med Wkly. 2013;143:w13826.

9. Zador PL, Krawchuk SA, Voas RB. Alcohol-related relative risk of driver fatalities and driver involvement in fatal crashes in relation to driver age and gender: an update using 1996 data. J Stud Alcohol. 2000;61(3):387-95.

10. Acworth A, de Roos N, Katayama H. Substance use and adolescent sexual activity. Appl Econ. 2012;44:1067-79.

11. Phillips-Howard PA, Bellis MA, Briant LB, Jones H, Downing J, Kelly IE, et al. Wellbeing, alcohol use and sexual activity in young teenagers: findings from a cross-sectional survey in school children in North West England. Subst Abuse Treat Prev Policy. 2010;5:27.
12. Balsa AI, Giuliano LM, French MT. The effects of alcohol use on academic achievement in high school. Econ Educ Rev. 2011;30(1):1-15.

13. Bradley BJ, Greene AC. Do health and education agencies in the United States share responsibility for academic achievement and health? A review of 25 years of evidence about the relationship of adolescents' academic achievement and health behaviors. J Adolesc Health. 2013;52(5):523-32.

14. Ellickson PL, Tucker JS, Klein DJ. Ten-year prospective study of public health problems associated with early drinking. Pediatrics. 2003;111(5 Pt 1):949-55.

15. Pillai A, Nayak MB, Greenfield TK, Bond JC, Hasin DS, Patel V. Adolescent drinking onset and its adult consequences among men: a population based study from India. J Epidemiol Community Health. 2014;68(10):922-7.

16. Hibell B, Guttormsson U, Ahlstom S, Balakireva O, Bjarnason T, Kokkevi A, et al. The 2011 ESPAD Report. The Swdish Council for Information on Alcohol and Other Drugs. Council of Europe. Pompidou Group. Stockholm 2011.

17. Hibell B, Guttormsson U. A supplement to the 2011 ESPAD Report. The Swedish Council for Information on Alcohol and Other Drugs. Council of Europe. The European Monitoring Centre for Drugs and Drug Adiction. Pompidou Group. Stockholm 2013.

18. Anonymous. Demografy in Brčko distrikt of $\mathrm{BH}$. Agency for Statistics of Bosnia and Herzegovina. Official register 2012; (5):2-5.

19. Stefanović A, Radulović O, Simonović Lj. Usage of alcohol by youth [In Serbian]. Medical Data. 2013;5(4):359-6.

20. Mihić J. Prevention of underage youth alcohol drinking. Formulation of the policy on the local level and experiences of the Istria region [In Croatian]. Kriminologija i socijalna integracija. 2008;16(2):1-124.

21. Lebedina-Manzoni M, Lotar M, Ricijaš N. Susceptibility to peer pressure and self-esteem [In Croatian]. Hrvatska revija za rehabilitacijska istraživanja. 2008;44(1)77-92. 